\title{
Aportes para el estudio de los orígenes del movimiento estudiantil en la Universidad de Buenos Aires: el caso del centro de estudiantes de Filosofía y Letras
}

Contributions to the study of the origins of the student movement at the University of Buenos Aires: the case of the Philosophy and Letters Student Union (1905-1918)

\author{
Pablo Buchbinder \\ Universidad de Buenos Aires-CONICET, Argentina \\ pbuchbin@retina.ar
}

\section{Resumen:}

El propósito del texto es el estudio de los orígenes del Centro de Estudiantes de la Facultad de Filosofía y Letras. Se analizan su organización, las características de sus asociados y sus primeros reclamos entre 1905 y 1918 . Las cuestiones relativas a la lucha por los puestos de profesor en las escuelas secundarias y las relaciones del Centro con los profesores y miembros del gobierno de la Facultad son especialmente estudiadas. También se analiza el vínculo con la política nacional. El trabajo está basado en el estudio de las revistas del Centro, de su libro de actas y de sus revistas y publicaciones.

Palabras Clave: Universidad, Estudiantes, Reforma, Profesorado.

\section{Abstract:}

The purpose of this article is to study the origins of the student union of the School of Philosophy and Literature. It analyzes its organization, members' features, and initial claims between 1905 and 1918. Issues concerning the struggle for teaching positions in high schools and the relations of the union with professors and members of the school government are specially scrutinized. The connection with the national policy is also analyzed. The article is based on the review of the union's magazines, its book of proceedings and publications.

KEYWORDS: College, Students, Reform, Faculty.

\section{INTRODUCCIÓN}

En el año 1900 se creó el primer Centro de Estudiantes de la Universidad de Buenos Aires en la Facultad de Derecho y Ciencias Sociales. Cinco años después se fundó el que agrupó a los alumnos de la Facultad de Ciencias Médicas. Unos años antes, en 1894, los jóvenes que cursaban estudios en la carrera de Ingeniería de la Facultad de Ciencias Exactas habían creado una organización que recibió el nombre de "La Línea Recta" (Dalmazzo, 1997: 51-71). Sin embargo, esta última, a diferencia de las anteriores, no situaba el aspecto gremial en el centro de sus reclamos sino que procuraba asistir a los estudiantes en las cuestiones vinculadas con la obtención de apuntes y la compra de libros. En 1903, los estudiantes de la Facultad de Ciencias Exactas configuraron un Centro de carácter similar a los que habían creado los de Ciencias Médicas y Derecho. A su vez, estas asociaciones, en su conjunto, sustituyeron a la Unión Universitaria, una agrupación que los estudiantes de la UBA, de sus por entonces tres facultades, habían creado en 1890. La Unión Universitaria era una organización comprometida fundamentalmente con la articulación de lazos de sociabilidad entre los alumnos de toda la Universidad, aunque también asumió progresivamente ciertos reclamos de naturaleza gremial o corporativa vinculados sobre todo con el régimen de exámenes y los pagos de derechos de matrícula. Los Centros de Estudiantes surgidos desde 1900, si bien nunca abandonaron la iniciativa en términos de organización de formas de encuentro y sociabilidad, mantuvieron en sus orígenes una connotación claramente gremial vinculada a la defensa de los derechos de sus asociados en tanto universitarios.

Las Facultades de Ciencias Exactas, Derecho y Ciencias Sociales y Ciencias Médicas existían desde la reorganización de la Universidad de Buenos Aires de finales del siglo XIX. A ellas se sumarían, en 1896, 
Filosofía y Letras, en 1908 Agronomía y Veterinaria, y en 1913, Ciencias Económicas. En los tres casos, y tempranamente, se organizarían también las agrupaciones estudiantiles. En 1908, los estudiantes de la UBA crearon su Federación Universitaria (FUBA) y recién en 1918, en el contexto del movimiento de la Reforma, se fundó la Federación Universitaria Argentina (FUA), que agrupó a representantes de las tres universidades nacionales y de las dos provinciales existentes por entonces. Podría señalarse que durante ese año culminó el proceso de creación y organización de las primeras agrupaciones gremiales representativas del movimiento estudiantil.

El presente artículo tiene como propósito contribuir al conocimiento de ese proceso a partir del estudio de la creación y los primeros pasos del Centro de Estudiantes de la Facultad de Filosofía y Letras de la UBA (CEFYL). Nos proponemos entonces explorar una serie de problemas relativos a su organización y sus actividades desde su fundación en 1905 hasta la Reforma de 1918. Los integrantes del CEFYL participaron en la creación de la FUBA, algunos de sus miembros intervinieron en los Congresos de Estudiantes Americanos celebrados entre fines de la primera década del siglo e incluso uno de sus Presidentes durante esta etapa, Gregorio Bermann, fue una figura central del movimiento reformista. Sin embargo, su trayectoria y sus primeros pasos no habían sido objeto hasta hoy de un estudio sistemático. La mayoría de los trabajos sobre el movimiento estudiantil de principios de siglo han focalizado su atención en las facultades de Derecho, Ciencias Médicas o Ciencias Exactas. En este sentido, creemos que este análisis puede contribuir a un conocimiento más adecuado del perfil de las organizaciones estudiantiles de principios de siglo y su relación con el Estado, la política y las autoridades e instituciones universitarias.

Cabe subrayar, en este contexto, que el estudio de los estudiantes porteños, sus organizaciones gremiales y su proyección política entre los primeros años del siglo y la Reforma han sido objeto de trabajos relevantes en los últimos años. Las contribuciones de Natalia Bustelo (2015) han mostrado, a través del análisis de sus revistas, la diversidad de sus orientaciones y opciones políticas e ideológicas, sobre todo en los tiempos anteriores e inmediatamente posteriores al movimiento de 1918. Los estudios de Luciana Carreño (2017, 2018) han relevado sus formas de sociabilidad, sus hábitos y costumbres, y reconstruido de manera exhaustiva los orígenes de sus organizaciones focalizando particularmente en los casos de las Facultades de Derecho y de Ciencias Médicas. Textos algo más antiguos, como el de Inés Rojkind (2007), han mostrado la intervención activa de los jóvenes, en particular los universitarios, en algunas de las controversias políticas de principios del siglo XX. Todos ellos se suman a importantes contribuciones aún anteriores, como las de Richard Walter (1968), Alberto Ciria y Horacio Sanguinetti (1968) o Juan Carlos Portantiero (1978). En este contexto puede incluirse también el reciente libro de María Fernando Lorenzo (2016), quien analizó desde la perspectiva de género las experiencias de estudiantes y académicas en diferentes facultades y carreras de la UBA durante la primera mitad del siglo XX.

Varios de los trabajos sobre el movimiento y las agrupaciones estudiantiles producidos durante los últimos años han insistido particularmente en mostrar las vinculaciones con el mundo más general de la política y en mostrar la intervención de los estudiantes en la arena pública. Menos atención, en cambio, ha recibido el estudio de la participación de estos en aquellas cuestiones vinculadas internamente con la vida universitaria o asociados a reivindicaciones más específicamente gremiales. Este texto procura recuperar integralmente estos aspectos, contemplando también, y en un primer plano, el análisis de dimensiones de naturaleza corporativa.

Este trabajo aspira a subrayar las peculiaridades del movimiento estudiantil temprano en la Facultad de Filosofía y Letras en el contexto de las organizaciones de principios de siglo. Inferimos que estos rasgos distintivos están fundados en algunos elementos en particular. En primer término, en la condición de docentes o aspirantes al ingreso a la docencia oficial o formal de la mayor parte de sus alumnos. La otra dimensión fundamental que, esperamos demostrar, condicionó, de modo decisivo, la acción del movimiento estudiantil de esta Facultad es el peso del alumnado femenino. Esto constituye un rasgo distintivo de la institución en el marco de un estudiantado universitario mayoritariamente masculino. Estas circunstancias marcarían, además, las orientaciones de la organización gremial de los estudiantes de la Facultad. Si 
bien aspiramos a demostrar que estos aspectos signarían el carácter de los reclamos estudiantiles también entendemos que, por otra parte, se inscriben en el tono fuertemente corporativo que empujó los reclamos de los universitarios argentinos de principios del siglo XX. De todas formas, también nos proponemos mostrar los modos en que aparece una agenda predominantemente política durante la segunda mitad de la década de 1910. La aparición de esta agenda encuentra, entendemos, su explicación en el impacto de la Primera Guerra Mundial, la inestabilidad económica y política que esta generó, los efectos de la sanción de la ley Sáenz Peña y la presencia de algunos destacados militantes socialistas entre los integrantes del CEFYL. El fracaso en el intento de avanzar en los reclamos motorizados por los estudiantes es interpretado también como uno de los factores de ese proceso de creciente politización

\section{LOS ORÍGENES DE LA FACULTAD, SUS ESTUDiANTES y SUS PRIMEROS RECLAMOS}

La Facultad de Filosofía y Letras fue fundada en 1896 en una época de cambios vertiginosos en la economía argentina, en su estructura social y en el sistema educativo en términos generales. Entre finales del siglo XIX y principios del XX, la Argentina experimentó un proceso de crecimiento acelerado, fundado en gran medida en un exitoso proceso de integración al sistema capitalista internacional sobre la base de la producción y exportación de bienes agropecuarios. Síntomas de estos cambios fueron, entre otros, el abrupto aumento de la población que, mientras entre 1810 y 1869 había aumentado tres veces, entre esta última fecha y 1914 creció más de cuatro (Devoto, 2010). El factor central que explica este crecimiento fue la inmigración. Los inmigrantes constituían el 25\% de todos los habitantes del país en 1895 y llegaron a un $30 \%$ en 1914. Durante este último año, la mitad de los habitantes del principal centro urbano del país, la ciudad de Buenos Aires, eran extranjeros. La urbanización constituyó otra de las expresiones de las transformaciones de la época. En 1914, de acuerdo con el censo realizado ese año, un 53\% de la población residía en centros urbanos de más de dos mil habitantes.

Estos cambios fueron acompañados de transformaciones sustantivas en la estructura social. Una de ellas fue la creciente concentración de la población económicamente activa en los sectores secundario y terciario, y la extensión de las clases medias, que englobaban aproximadamente por entonces a un tercio de la población total (Devoto, 2010). Este crecimiento y el consiguiente proceso de complejización de la estructura social revelaban la presencia de un dinámico proceso de movilidad social que constituyó otro signo característico de la historia de la sociedad argentina de esta etapa.

En los procesos de integración y movilidad social, el sistema educativo, en sus distintos niveles, cumplió un papel fundamental. En principio, debemos tener presente la sanción en el año 1884 de la ley 1420, que instituyó en el ámbito nacional -al que por entonces pertenecía también la ciudad de Buenos Aires- la educación primaria laica, gratuita y obligatoria bajo responsabilidad del Estado. La incorporación masiva de los hijos de los inmigrantes no puede desvincularse del papel de la escuela pública. La enseñanza secundaria y universitaria quedaron aún reservadas para sectores reducidos. Sin embargo, el número de estudiantes en este último nivel experimentó un crecimiento sostenido en los primeros años del siglo. Los estudiantes universitarios que no llegaban a 2000 en 1906 en 1920 ya superaban los 12000 (Terrén de Ferro, 1985). En el imaginario de gran parte de los inmigrantes, la educación universitaria y fundamentalmente la obtención del título habilitante -médico, abogado o ingeniero- conformaba un instrumento central en el proceso de ascenso social. Por otro lado, también en la década de 1880, el sistema universitario experimentó una transformación de su ordenamiento institucional. La primera ley universitaria nacional fue sancionada en 1885. Estableció un gobierno para las universidades centrado en las facultades y permitió una autonomía relativa que encontró su principal límite en el hecho de que el Poder Ejecutivo se reservó la atribución de designar a los profesores titulares a partir de una terna elevada por las facultades y ratificada por el Consejo Superior. Sobre la base de esta ley, las universidades dictaron sus estatutos. Estos impusieron para el gobierno de las facultades, centro de la vida universitaria, consejos académicos signados por la presencia de miembros 
vitalicios y por la limitación de la participación de los profesores a un tercio de los cargos. Más allá de esto, es importante resaltar que el sistema universitario argentino se constituyó sobre la base del molde napoleónico. En este sentido, la función de la Universidad se centró en la emisión de títulos habilitantes para el ejercicio de las profesiones liberales. La formación profesional y la expedición de los títulos constituyeron el eje de la actividad de las instituciones de enseñanza superior. Estos aspectos estuvieron en el origen de las disputas y controversias que animaron la vida universitaria argentina, y sobre todo porteña, en los primeros años del siglo.

La Facultad de Filosofía y Letras fue creada, así, en el marco de una política tendiente a limitar el carácter eminentemente profesionalista del mundo universitario, centrado casi fundamentalmente en la formación de médicos, abogados e ingenieros. Inicialmente, se dispuso que se limitase a otorgar un título, el de Doctor en Filosofía y Letras, que no tenía ninguna finalidad práctica ni habilitaba para el ejercicio de ninguna profesión en particular. La Facultad fue pensada como el lugar de los "estudios desinteresados" en el marco de un sistema de educación superior "eminentemente utilitarista" (Halperín Donghi, 1962; Buchbinder, 1997). El plan de estudios se caracterizaba por la formación común en varias disciplinas humanísticas, predominando los estudios literarios, filosóficos e históricos. Pocos años después de su fundación, se estableció que la Facultad otorgaría también títulos de profesor en cada una de estas tres áreas a quienes ya ejerciesen la docencia en el ámbito de la enseñanza media, a partir de la aprobación de un número limitado de asignaturas.

Los alumnos de cada una de las facultades de la UBA presentaban características distintivas. De modo muy simplista, puede señalarse que entre los estudiantes de Medicina se hacía notar sobre todo la presencia de los hijos de inmigrantes recientes, mientras entre los de Derecho se visualizaba la de miembros de familias de las élites más tradicionales relacionadas estrechamente con la vida política e institucional. El predominio casi absolutamente masculino era un rasgo evidente del estudiantado tanto en estos casos como en el de Ciencias Exactas, por entonces dedicada esencialmente a la formación de ingenieros. El objetivo de acceder al título habilitante orientaba, además, gran parte de las acciones y estrategias colectivas de los estudiantes.

Los de Filosofía y Letras presentaban a su vez algunos rasgos peculiares que los diferenciaban de sus compañeros del resto de la Universidad. Esta peculiaridad incidiría también en su agenda de reivindicaciones y reclamos. Una de estas características era su número limitado, mucho menor al de las otras tres instituciones. Filosofía y Letras era la Facultad que congregaba en los primeros años del siglo al menor número de estudiantes. Justamente esta última situación conspiró contra la viabilidad de la institución que, en más de una oportunidad, estuvo cerca del cierre. En su Memoria de 1900, con preocupación, el Rector destacaba que sólo 12 alumnos se habían inscripto en los cursos de primero y segundo año mientras 13 lo habían hecho en los de tercero y cuarto. ${ }^{1}$ Sólo con el paso del tiempo y en la medida en que logró configurarse como una institución que, al tiempo que formaba especialistas en las disciplinas humanistas, también otorgaba títulos de profesor pudo asegurar finalmente su subsistencia, obtenida entonces gracias al incremento en el número de alumnos. Mientras en 1906 había 84 estudiantes, en 1917 ya llegaban a 258. Pero aún con este aumento, la diferencia con respecto a otras facultades en términos de matrícula siguió siendo muy significativa a lo largo de todo el período aquí analizado. Ese mismo año, un artículo publicado en Verbum señalaba que por entonces Ciencias Médicas contaba con 4100 alumnos y Derecho con $1383 .{ }^{2}$ Por otro lado, también debe tenerse en cuenta que, entre 1900 y 1905, sólo el 1\% de los títulos entregados por la Universidad correspondieron a la Facultad (Lorenzo, 2016: 31).

Carlos Ibarguren, jurista y profesor de Historia argentina de la institución, consignó en sus Memorias una descripción sucinta de los estudiantes de la Facultad en los primeros años del siglo: "los alumnos de la Facultad eran pocos, generalmente maestros y maestras que buscaban obtener el título de profesor que les mejoraba su situación en el magisterio y algunos amantes de la cultura superior que se inscribían en los cursos para doctorarse o que los seguían con el propósito de instruirse" (Ibarguren, 1977 [1955], 237). En este sentido es importante destacar que, a diferencia de lo que sucedía en otras facultades, en las que los egresados de las escuelas normales debían rendir exámenes especiales ya que en principio sus títulos no los 
habilitaban para acceder a los estudios universitarios, en el caso de Filosofía y Letras su acceso fue facilitado a partir de diversas resoluciones especiales del Consejo Académico. Este hecho permitió que la institución albergase, entre sus alumnos, a un número importante de egresados de dichas escuelas que, simultáneamente, se desempeñaban como docentes activos. Rafael Berruti (1996), en un breve texto sobre los orígenes de la Facultad, reconstruido a partir de testimonios de ex-alumnos, registró, entre los primeros 28 ingresantes a la institución 10 egresados de escuelas normales, 3 abogados y un estudiante de medicina. La condición de maestros y profesores fue esgrimida a menudo por los estudiantes de la Facultad a la hora de elevar algunas de sus primeras peticiones colectivas. En 1900, al solicitar una modificación de los horarios sostuvieron que, "como es sabido, la mayor parte de los que seguimos cursos en esta Facultad somos empleados de las escuelas comunes de esta capital". ${ }^{3}$ Tiempo después pidieron la postergación de los exámenes del mes de diciembre argumentando que ellos mismos debían ocuparse de la toma de pruebas en las escuelas. El otro rasgo peculiar que distinguía claramente, como ya señalamos, a los estudiantes de Filosofía y Letras en el contexto del mundo universitario porteño era la amplia presencia femenina en un ámbito poblado mayoritariamente por hombres. En la primera promoción, de los 9 egresados, 4 eran mujeres (García, 2006: 133-172). Como ha señalado María Fernando Lorenzo (2016: 32), para muchas mujeres la apertura de la Facultad de Filosofía y Letras implicó la oportunidad de acceder a la educación superior. Cabe recordar aquí que recién en 1889 egresó la primera médica de la Universidad de Buenos Aires, Cecilia Grierson, en 1910 la primera abogada, Celia Tapias, y en 1918 la primera ingeniera, Elisa Bachofen. Como ha destacado Dora Barrancos (2008), la Universidad de finales del siglo XIX estaba básicamente vedada a las mujeres aun cuando no existía ninguna forma legal que impidiera su acceso. De los 6186 títulos otorgados entre 1900 y 1915, sólo 159 correspondían a mujeres (Suárez, 2012: 143-183).

Debe señalarse también, en este contexto, que los estudiantes de la Facultad, antes de la organización de su Centro, durante la primera década de vida de la institución, hicieron llegar, de manera colectiva, aunque informal, diversos reclamos ante las autoridades de la Facultad y la Universidad. Los estudiantes exigieron nuevos turnos de exámenes, cambios en los sistemas de horarios y mayor flexibilidad en el régimen de correlatividades, entre otras cuestiones. Muchas de sus peticiones se asemejaban a las de los estudiantes de otras facultades. Sin embargo, debe señalarse que los principales pedidos estuvieron condicionados por cuestiones que afectaban sobre todo sus posibilidades de inserción en las escuelas secundarias (Buchbinder, 1997). En este sentido, más que impregnado por motivaciones políticas sus reclamos mantenían una tonalidad claramente corporativa asociada a la defensa y prerrogativas vinculadas con el título y con la validez de los estudios desarrollados en la institución. En este contexto, y de manera reiterada, los estudiantes reclamaron el apoyo de las autoridades de la Universidad con el propósito de obtener ventajas a la hora de acceder a cargos docentes en el sistema de enseñanza secundaria. De alguna manera, este tipo de reclamo revelaba también el fuerte lazo que unía a los estudiantes con los egresados, aspecto que es posible observar también en otras organizaciones estudiantiles, como las relacionadas con las carreras de Medicina e Ingeniería, vinculadas de manera estrecha con el Círculo Médico Argentino y el Centro Nacional de Ingenieros, respectivamente.

En 1899, un grupo de alumnos de cuarto año presentó una nota al Decano de la Facultad solicitando que las autoridades de la institución se preocupasen por fijar rumbos a quienes estaban terminando sus estudios. Ese reclamo, aclaraban los peticionantes, no implicaba desconocer que el "fin más noble y elevado de la institución residía en la perfección moral”, pero consideraban que era también justo que el capital intelectual acumulado en los años de estudios encontrase un medio de exteriorización práctico. La incógnita principal, señalaban los estudiantes, radicaba en saber si los estudios cursados en la Facultad les otorgarían derechos especiales en la provisión de las cátedras sin recurrir al desprestigiado sistema de las “recomendaciones”. En este sentido, se preguntaban si al aspirar al desempeño de una cátedra de Instrucción Superior serían sometidos a concurso, incluso en las materias en que hubiesen dado pruebas de suficiencia en la Facultad. Más tarde, y animados por los mismos propósitos, presentaron otra nota al Decano pidiéndole que gestionase ante los poderes públicos 
el empleo inmediato y seguro de los egresados. Se quejaban entonces de que en el Plan de Enseñanza General presentado al Congreso por el Poder Ejecutivo para designar profesores en los establecimientos de enseñanza media no se contemplase de manera particular la situación de los egresados de la Facultad. En este sentido, los alumnos insistieron con frecuencia para que el Decano interviniese con el propósito de asegurar la preferencia para los graduados en el otorgamiento de las cátedras en los establecimientos de enseñanza media. ${ }^{4}$

\section{LOS ORÍGENES DE LA ORGANIZACIÓN ESTUDIANTIL: LA CONSTRUCCIÓN DE UNA AGENDA GREMIAL}

El CEFYL fue fundado en el Salón de Actos Públicos del diario La Prensa el 30 de septiembre de 1905. Sus fundadores, reunidos en Asamblea, sostuvieron que la nueva organización tendría, como propósito central, defender los intereses de los estudiantes, publicar una revista, crear una Biblioteca de "autores nacionales", estimular el desarrollo intelectual del país por medio de "concursos literarios" y organizar conferencias públicas. ${ }^{5}$ En la reunión participaron personajes que cumplirían un papel destacado en la vida pública del país pero también de la Universidad y de la misma Facultad. Entre ellos figuraban Emilio Ravignani, Alfredo Bianchi y Roberto Giusti. Francisco D’ Andrea fue electo su primer Presidente. El CEFYL mostraba, además, un rasgo que tempranamente lo diferenciaría del conjunto casi exclusivamente masculino que signaba la mayoría de las agrupaciones similares de la UBA. El listado de sus 49 fundadores muestra la presencia de 21 mujeres y revela también la participación de una de ellas como vicepresidenta, Celestina F. de Frutos, circunstancia extraordinaria entre las organizaciones estudiantiles de la época. ${ }^{6}$ Esta presencia activa femenina se mantendría a lo largo del período aquí estudiado, revelando además la voluntad de las estudiantes de la Facultad de participar y sostener el Centro y, obviamente, de incidir en sus estrategias. En 1916, por ejemplo, la lista de 61 socios activos mostraba la presencia de 28 mujeres.

El CEFYL fue fundado, por otra parte, en un momento particular signado por fuertes controversias entre los estudiantes de las Facultades de Derecho y Ciencias Sociales y los de Ciencias Médicas -ya organizados gremialmente a través de sus respectivos centros- y las autoridades de la UBA. Estos conflictos, algunos particularmente violentos y que llevaron a la paralización parcial de gran parte de las actividades de la casa de altos estudios, culminaron con una Reforma de los Estatutos en 1906. Esta terminó con los Consejos Académicos integrados hasta entonces, como ya señalamos, por miembros vitalicios y con la posibilidad de que los integrantes de los mismos Consejos eligiesen a sus futuros integrantes. A partir de entonces los Consejos, denominados ahora Consejos Directivos, serían electos sobre la base de una propuesta del cuerpo de profesores titulares y se renovarían periódicamente.

Durante esta primera etapa, las reivindicaciones corporativas de los estudiantes universitarios se impusieron sobre la intervención en la política nacional y sobre el debate en torno a cuestiones religiosas. Tanto en Derecho, como en Ciencias Médicas o en Ciencias Exactas, los estudiantes centraron sus protestas en aspectos relativos a diferentes dimensiones del régimen de estudios. A la vez, cuestionaron la composición política del gobierno universitario al que, crecientemente, responsabilizaron de la situación académica. En este sentido, es preciso recordar aquí, una vez más, la preeminencia en la Argentina, como en otros países de América Latina, de un modelo profesionalista que inducía a las actividades universitarias a concentrarse en la expedición de los títulos que, a su vez, habilitaban para el ejercicio de una profesión liberal. Además, el sistema de enseñanza se basaba en el control cerrado de la universidad por parte de reducidas élites ligadas al Estado y la política. En este marco, los estudiantes estaban sometidos a un régimen disciplinar en el que la función del examen, el control de la asistencia obligatoria a clase y un sistema de correlatividades rígidamente configurado condicionaban el desarrollo de los estudios y ponían innumerables obstáculos en el camino que llevaba al ansiado título profesional. Un factor adicional que debemos tener presente aquí se vincula con el hecho de que la posibilidad de llevar a cabo estudios universitarios estaba limitada, entre otros factores, por la obligación 
de pagar derechos de matrícula. En estos primeros años del siglo, los estudiantes no reclamaron la imposición estructural de la gratuidad de la enseñanza universitaria. Sin embargo, los pedidos específicos de exención del pago de la matrícula constituían elementos recurrentes entre sus solicitudes. En relación con los exámenes, también debe recordarse que los estudiantes debían, en principio, en todas las facultades, rendir al final de su carrera los llamados exámenes generales. Se graduaban con estas pruebas que conllevaban la obligación de dar cuenta de todos los contenidos aprendidos a lo largo de aquella. Tempranamente, los estudiantes de Filosofía y Letras, como los de otras facultades, exigieron una reglamentación especial de estos exámenes y luego su supresión, lo que se obtuvo en el caso de la Facultad sólo con la Reforma de 1918. (Buchbinder, 1997).

Así, esta intensa orientación del movimiento estudiantil hacia reivindicaciones corporativas desligadas de aspectos más específicamente políticos puede advertirse, entonces, también en esta primera etapa de organización del CEFYL. Muchos de los primeros pedidos y exigencias se vinculaban con aspectos relativos directamente al régimen de estudios y revelan una clara afinidad con los que motivaban las protestas de los estudiantes de otras facultades. Las dificultades para lograr una respuesta positiva de parte de las autoridades universitarias hicieron que los reclamos debieran ser reiterados a lo largo del período aquí analizado. Una de las cuestiones principales estaba vinculada con el ya mencionado régimen de exámenes. Aspectos relativos a estos problemas fueron los que provocaron las protestas estudiantiles en Derecho y Medicina, que llevaron, a la vez, en 1906, a la modificación de los estatutos de la UBA. Como ya señalamos, un primer tema era el relativo a los exámenes generales, práctica resistida de manera recurrente por los estudiantes. En la sesión siguiente a la creación del Centro, en los primeros días de 1906, los estudiantes resolvieron pedir una reglamentación más detallada de dichos exámenes, pero al mismo tiempo cuestionaron su existencia de manera decidida. En agosto de ese año, en una nota al Decano, sostuvieron que "sólo obligan a un esfuerzo memorístico del que ningún beneficio nace, ni para la institución ni para el ex alumno". ${ }^{7} \mathrm{Al}$ mismo tiempo, el tema de la postergación de los turnos de examen y la habilitación de fechas complementarias constituyó también uno de los pedidos elevados con mayor frecuencia, fundamentado, en muchos casos, como ya comentamos, en las actividades docentes de los mismos alumnos. La supresión de la obligatoriedad de la asistencia a clase, por otro lado, conformó otro de los reclamos habituales. Fue sostenido, como el tema de los exámenes a lo largo de toda esta etapa, aludiendo a ejemplos externos, como el caso de las universidades alemanas, donde aquella era optativa. A través del cuestionamiento al sistema de exámenes y a la asistencia obligatoria, los estudiantes manifestaron su disconformidad con aspectos sustantivos del régimen universitario. Cabe recordar aquí que la supresión de la asistencia obligatoria junto con la docencia libre y la participación en la elección de los miembros del gobierno universitario constituyeron las tres reivindicaciones centrales de los estudiantes en tiempos de la Reforma.

Pero, al mismo tiempo, otras reivindicaciones y reclamos que tuvieron un papel significativo en la organización y actividades de otros Centros estudiantiles sólo alcanzaron aquí un papel marginal. Puede observarse esta situación sobre todo en el caso de las solicitudes por los derechos de matrícula que estaban obligados a abonar los estudiantes. El escaso número de alumnos que congregaba la institución llevó a que las autoridades universitarias, con el propósito de estimular el crecimiento del estudiantado, eximieran, a menudo, a los alumnos de la Facultad del pago de estos derechos.

El CEFYL también se preocupó por cumplir diverso tipo de tareas de asistencia a los estudiantes, hecho que constituiría un sello particular de estas organizaciones gremiales en la larga duración. La impresión de apuntes y sobre todo la transcripción de las clases de los profesores fue una actividad que asumió desde su creación. La publicación de notas de clase -en particular en Latín y Biología- que se distribuían gratuitamente y la reproducción mimeografiada de algunos cursos constituyeron aspectos que absorbieron parte de los esfuerzos de los asociados. A ellos se sumaron otros, como el pedido de ampliación de los horarios de acceso a la biblioteca o la exigencia del aumento de su patrimonio bibliográfico. A lo largo de este período también los estudiantes insistieron en la necesidad de acortar la carrera (afirmaban que era excesivamente larga) y a vanzar en el proceso de especialización mediante la modificación del plan de estudios 
Cualquier estudiante, argumentaron a través de un artículo en $V e r b u m$, requería de al menos 8 años para terminarla. En este marco, también insistieron en lo negativa que resultaba la "heterogeneidad de los estudios". En este sentido, a principios de la década de 1910 afirmaron la necesidad de dividir formalmente los estudios de la Facultad en tres doctorados: en Filosofía, Letras e Historia.

Por otra parte, y gracias a un disciplinado e intenso trabajos de sus integrantes, el CEFYL mantuvo un funcionamiento regular durante el período aquí analizado. Llevó a cabo periódicamente las sesiones de su Comisión Directiva y de las Asambleas de asociados, y observó rigurosamente su reglamento. Las transgresiones a sus normas internas, en particular a partir de los conflictos agudos entre sus miembros o derivados de la intromisión en hechos de política nacional, fueron rigurosamente observados. También se ocuparon de supervisar el pago de las cuotas de los integrantes, que eran fundamentales, entre otros aspectos, para el mantenimiento de las publicaciones. Al mismo tiempo, los miembros de la organización siguieron con atención y participaron activamente en las instancias de creación y conformación de las federaciones estudiantiles, tanto de la FUBA como, posteriormente de la FUA. Además, trataron de mantener de manera regular vínculos con organizaciones estudiantiles nacionales e internacionales.

Una atención especial merece el estudio de las revistas que el CEFYL editó con notable regularidad desde 1906. Primero con el título de Boletín del Centro de Estudiantes, desde 1911 con el de Revista del Centro de Estudiantes de Filosofía y Letras y, finalmente, a partir de 1912 bajo el nombre de Verbum. A través de ellas la organización hizo conocer y difundir sus actividades. Las revistas funcionaron como una instancia de comunicación del organismo con sus asociados. Allí se publicaron, en particular desde mediados de la década del 10, las actas del Centro y sus resoluciones. Pero probablemente fue la publicación de las clases la más importante de las actividades que canalizaban estas revistas, sobre todo en su primera década. En estas publicaciones se dieron a conocer lecciones de los profesores y textos para las clases. No todos facilitaban los materiales, pero es posible leer allí fragmentos de los cursos de Geografía Física de Enrique Delechaux, de Geografía Económica de Clemente Fregeiro, de Estética de Camilo Morel, de Arqueología Americana de Samuel Lafone Quevedo o de Antropología de Roberto Lehmann Nitsche. Más tarde, sobre todo a partir de la aparición de Verbum, la publicación de artículos originales y la inserción de la revista en el circuito de las publicaciones culturales de la época adquirió una importancia sustantiva.

Finalmente, el Centro también asumió desde sus publicaciones la defensa global de la institución, de sus tareas y funciones. En un "Manifiesto" publicado en Verbum se señalaba que no era bueno "que el país se conozca sólo por su balanza comercial reflejada en los guarismos de sus estadísticas o a través de la muchachada ignorante o bullanguera que se divierte en los music-halls de París" ${ }^{8}$ En oposición a rasgos característicos de sectores juveniles vinculados a la élite o a quienes frecuentaban otras facultades fueron construyendo su identidad los estudiantes de Filosofía y Letras. Defendieron en este contexto, finalmente, también la necesidad de la profesionalización de las actividades intelectuales, subrayando el papel central que en este proceso cumplía la Facultad

\section{EN DEFENSA DE ESTUDIANTES Y GRADUADOS: LA LUCHA POR EL RECONOCIMIENTO DE LOS TÍTULOS}

En el caso del CEFYL hay un aspecto que marca un matiz particular en relación con el resto de las organizaciones estudiantiles y era la presión que ejerció para lograr el reconocimiento de los títulos por parte del Estado a la hora de la provisión de cátedras en las instituciones de enseñanza secundaria. En este sentido, la organización retomó reivindicaciones que, como señalamos, los estudiantes habían formulado antes de la constitución del Centro. También en este caso la disputa por la validez de los títulos, y la necesidad de que la institución gremial se comprometiese activamente en su defensa, configura una característica hasta cierto punto particular de los estudiantes de Filosofía y Letras. La insistencia y la reiteración permanente de este tipo de reclamos permite advertir que tanto estudiantes como graduados encontraron a lo largo de 
toda esta etapa dificultades permanentes en su intento de hacer que sus diplomas fuesen tenidos en cuenta de manera privilegiada en el momento de proveer las cátedras. Cabe destacar que el surgimiento de la Facultad y del Instituto Nacional del Profesorado más tarde conllevó un cambio, aunque evidentemente limitado y resistido, en el modo de selección y reclutamiento de los profesores de las escuelas secundarias. La posesión de un diploma expedido por estas instituciones implicó, sin duda, una alteración en los modos tradicionales de selección del profesorado que, seguramente, encontró fuertes resistencias.

Cabe destacar, en este sentido, que hasta 1903 no existía en la Argentina una institución responsable de la formación y titulación de profesores para el sistema de enseñanza media (Pinkasz, 1992: 59-82). En 1904 se creó el Seminario Pedagógico, que tenía como función central formar a los profesores y que en principio sólo les brindaba la instrucción pedagógica. Sin embargo, tiempo después, asumió la tarea de otorgar formación disciplinar. Este seminario se convirtió más tarde en el Instituto Nacional del Profesorado Secundario. Entre 1906 y 1907 fue anexado a la Facultad, pero luego de ese año volvió a ser separado, con lo que se generó una cierta competencia entre ambas instituciones. Las peticiones elevadas periódicamente por el CEFYL ante las autoridades de la Facultad y la Universidad solicitando su apoyo para obtener prioridad para estudiantes y egresados en la provisión de los cargos revelan que los títulos de la casa de estudios no llegaban a obtener un reconocimiento particular en el ámbito de la enseñanza secundaria. Es llamativo, por otro lado, que tampoco alcanzasen ese reconocimiento en el mismo espacio de la UBA. En julio de 1907, los estudiantes resolvieron dirigirse al Consejo Superior y pidieron que se diese "especial preferencia a los alumnos y egresados de la Facultad en la distribución de las cátedras de Gramática, Literatura, Historia, Geografía y Filosofía del Colegio Nacional Central". ' En 1915, el CEFYL debió elevar una protesta por la exclusión de dos egresados de la institución en el Concurso para proveer de un Profesor de Latín a una Cátedra en ese Colegio Nacional, dependiente ahora de la UBA. Afirmaban que "los egresados de la Facultad de Filosofía y Letras de Buenos Aires, competentes desde luego, por el título conquistado para dictar la materia de sus estudios están, al menos deben estar, primero que cualquier extraño, diplomado o no, fuera de esta casa". ${ }^{10}$

Por otro lado, recordemos aquí que una característica particular del movimiento estudiantil de principios de siglo fue, justamente, la estrecha relación que los estudiantes establecieron con los miembros de las asociaciones que agrupaban a los egresados. En los casos de médicos, farmacéuticos y odontólogos era habitual que egresados y estudiantes exigiesen, de modo reiterado, que el Estado vigilase el ejercicio ilegal de esas profesiones por personas no tituladas. En el de Filosofía y Letras, el aspecto que unía a estudiantes y egresados estuvo sobre todo vinculado al reconocimiento de los títulos en el proceso que llevaba a la obtención de las cátedras. Este hecho los obligaba a interactuar y reclamar permanentemente ante las autoridades. En este sentido, debe subrayarse que en mayo de 1914 los miembros de la Comisión Directiva se propusieron constituir el Centro en gestor también de los intereses de los egresados ante los poderes públicos encargados del "otorgamiento de cátedras en instituciones nacionales". ${ }^{11}$

La lucha por el reconocimiento de los diplomas recorre toda la primera etapa de la historia del Centro. Se trata de una cuestión que, por otro lado, tuvo también una incidencia fundamental en la construcción de la identidad de los primeros estudiantes de la Facultad. Fue central, en el mediano plazo, en la estructuración de su vínculo con la política nacional, el Estado y las mismas autoridades universitarias. Puede señalarse que esa identidad se definía ya desde el ingreso a la institución, por un lado, a partir de su vinculación con el sistema de enseñanza y de su condición de maestros y profesores, pero por otro también en defensa de una carrera profesoral regida por criterios meritocráticos. Al reclamar una ley orgánica del Profesorado Secundario, insistieron en que esta debía dar preeminencia en el acceso a los cargos "a los diplomados, entre éstos a los mejores y todos debían ser seleccionados con escrupulosa rectitud." 12 Durante 1912, los estudiantes obtuvieron por parte del Ministerio Nacional un reconocimiento, que se complementó con otro decreto de provisión de cátedras en 1915 que llevaba la firma del Ministro Saavedra Lamas. Sin embargo, ninguna de las dos disposiciones resolvió el problema. Por eso, junto con los graduados de otras instituciones, 
como el Instituto Nacional del Profesorado, resolvieron conformar, tiempo después, una liga "Pro Ley del Profesorado Secundario".

Como acabamos de señalar, en la lucha por el reconocimiento de los diplomas los estudiantes defendieron una visión meritocrática del acceso a los cargos de profesor que se oponía a los criterios clientelares vinculados con el sistema político, que eran, en definitiva, según señalaban, los que primaban en los procesos de selección. Estos criterios eran, a la vez, una derivación de la "política criolla". El tema, como señalamos, les permitía además situarse frente a problemáticas más generales de la política y construir un perfil que oponía -en una lucha desigual- a quienes eran merecedores de los cargos frente a quienes finalmente los ocupaban por sus vínculos con la política. Por eso insistían en hacer primar "nuestros méritos y diplomas sobre los otros entronizados gracias al arma que constituye la mayor de las lacras nacionales: la política y el favoritismo". ${ }^{13}$ Este motivo, permitía, además, encontrar un ámbito de confluencia y consenso entre los estudiantes y las autoridades de la Facultad.

¿En qué medida la discriminación por género operaba en estas prácticas que eran, por otro lado, cuestionadas firmemente por una organización como el CEFYL en la que casi la mitad de sus socios activos eran mujeres? Se trata de una pregunta de difícil respuesta. La cuestión de género no fue, por lo general, esgrimida explícitamente en los reclamos de la organización por el acceso a las cátedras que, seguramente eran ocupadas, en la mayoría de los casos, por varones sin títulos ni estudios especializados. Como ha argumentado Dora Barrancos $(2008,67)$, a principios de siglo, entre los profesores de la escuela secundaria, el número de varones superaba ampliamente a las mujeres. En este sentido, ha señalado que los bachilleratos constituían ambientes donde las mujeres no ingresaban ni como alumnas ni como profesoras, en términos generales. La situación era, de todos modos, diferente en las escuelas normales. Pero es importante, en este sentido, tener presente un episodio sucedido en la Facultad a principios de 1910 y que protagonizó Raquel Camaña, una destacada egresada de la Escuela Normal de La Plata y ex alumna de la Facultad, que contaba con vastos antecedentes académicos y científicos. Camaña solicitó al entones Decano, José Nicolás Matienzo, el acceso a la suplencia de la Cátedra de Ciencia de la Educación. La respuesta a su solicitud fue una comunicación en la que se sostenía que la institución había aplazado una decisión sobre el pedido“(...) en la duda de si es posible abrir esa carrera, por ahora al sexo femenino". Elevó entonces Camaña un reclamo ante el Consejo Superior. La defensa de los méritos académicos, sin ninguna distinción de género, se situaba en el centro de su escrito. Allí planteaba el interrogante: ¿ cómo era posible "hablar de libertad de enseñanza en un país donde los puestos públicos educacionales no son accesibles a todos sin otra condición que la idoneidad?". ${ }^{14}$

Indudablemente, aspectos relativos a la discriminación de género, que atraviesan la historia universitaria de esos años, como ha mostrado claramente en su libro María Fernando Lorenzo (2016), adquirieron por la composición del estudiantado un matiz particular en la Facultad e incidieron en las estrategias de su movimiento estudiantil. Es importante recordar aquí que algunas de las protagonistas centrales del movimiento feminista en la Argentina de principios de siglo -considerablemente moderado- frecuentaron la institución como alumnas. Elvira López, por ejemplo, integrante de la primera camada, dedicó su tesis doctoral al estudio del movimiento feminista y fue una de las organizadoras del Primer Congreso Femenino Internacional celebrado en Buenos Aires en 1910. Por otro lado, la activa participación de las mujeres en el CEFYL permite advertir una clara excepción a la situación de fuerte e intensa subordinación que las mujeres conservaron durante estos años en la mayoría de las organizaciones estudiantiles de la UBA, como ha observado convincentemente en sus trabajos Luciana Carreño (2018). Las mujeres participaban activamente en las reuniones, tomaban la palabra y ocupaban periódicamente cargos en los organismos directivos de la organización, aun cuando no llegaron durante estos primeros años a ocupar el máximo cargo en ella. De todos modos, como ya señalamos, su presencia allí se hizo notar claramente en el hecho de que el primer vicepresidente fuese una mujer, Celestina F. de Frutos. 


\section{El CEFYL ante las aUtoridades y profesores de la Facultad}

El sostenimiento del vínculo con las autoridades de la Facultad y con su cuerpo de profesores constituyó, como en los casos de otros centros, una de las principales preocupaciones del CEFYL. En líneas generales, es posible observar cierta deferencia hacia las primeras a lo largo del período aquí analizado. Más allá de algunas tensiones menores es raro encontrar, incluso en tiempos de la Reforma, un cuestionamiento radical a aquellas. En 1911, los integrantes del Centro sostuvieron que una de las funciones de su organización consistía en establecer entre la masa estudiantil y las autoridades de la Facultad el "vínculo que forzosamente debe existir en gaje a la más elemental armonía docente". ${ }^{15}$ Pocos años más tarde, dirigiéndose al Consejo Directivo afirmaban que el CEFYL estaba "animado de los mejores propósitos", que tenía confianza en ese "consejo" y mucha fe en su Decano, "para quien no tiene sino palabras de elogio" ${ }^{16}$ Incluso, en tiempos de la Reforma, la gestión del interventor Juan Agustín García fue recibida favorablemente y los estudiantes apoyaron la elección, como primer Decano reformista, del candidato que también respaldaron los profesores, el médico y filósofo Alejandro Korn.

La relación con los profesores estuvo signada por otras variables. En este sentido es importante recordar que una característica particular de los movimientos estudiantiles de los tiempos previos y posteriores a la Reforma fue una especial preocupación en torno a los modos de armado de las ternas sobre las que el PE designaba a los profesores titulares, como en torno a la designación de los suplentes por parte de los Consejos que gobernaban las facultades. Las quejas por la conducta de los profesores y en particular por sus arbitrariedades a la hora de los exámenes constituyeron, particularmente en el período inmediatamente previo y posterior al movimiento de 1918, un motivo que galvanizó con fuerza las protestas estudiantiles. En el caso de la Facultad de Ciencias Médicas, una de las razones que originó el conflicto de 1905 -que derivó en una primera reforma estatutaria- estuvo relacionada con la exclusión de la terna para proveer de un profesor titular a la cátedra de Clínica Médica de un conocido profesional de la ciudad. Julio Méndez, el médico en cuestión, era, además profesor suplente de la casa y los estudiantes se movilizaron en su defensa por su idoneidad y su prestigio. En este sentido, actuaron en estrecha relación con los representantes de las corporaciones profesionales (Sousa, 2007: 141-162). Para los miembros de estas últimas, en particular en el caso de los médicos, la incorporación como profesores titulares de la Facultad tenía un papel relevante en la construcción del prestigio profesional.

Es importante recordar aquí que la Universidad contemplaba en principio, en esta época, dos grandes categorías de docentes: profesores titulares y suplentes. Durante el período previo a la Reforma, y sobre todo en Filosofía y Letras, las diferencias entre las dos categorías eran significativas. Los profesores titulares tenían la responsabilidad de la dirección de la enseñanza. Sus cargos eran prácticamente inamovibles, ya que una vez designados sólo el fallecimiento o la renuncia afectaba su continuidad. Eran nombrados, como ya destacamos, por el Poder Ejecutivo a partir de una terna elevada por la Facultad y ratificada o modificada luego por el Consejo Superior.

La potestad de designar a los profesores suplentes radicaba, en cambio, directamente en el Consejo Académico hasta 1906 y luego en los Consejos Directivos de las facultades. Los suplentes presentaban una jerarquía menor que los titulares. Era habitual que sus clases no integrasen el temario de los exámenes y tampoco cobraban por sus tareas. Pero podían reemplazar al titular y tenían además algunas prerrogativas para integrar la terna a partir de la que se designaba a aquel si el cargo quedaba vacante. Por esa razón la designación como profesor suplente constituía una aspiración relativamente importante para quienes deseaban seguir una carrera como profesor universitario o como docente en términos generales.

En el caso de Filosofía y Letras es probable que haya que incorporar algunos elementos particulares para comprender adecuadamente el papel que el vínculo con los profesores, tanto titulares como suplentes, jugó en las estrategias y acciones del movimiento estudiantil. A la vez, estos elementos deben relacionarse con las ya mencionadas características peculiares del estudiantado de la Facultad, en su mayor parte personas dedicadas 
a la docencia o que aspiraban a continuar su carrera en el ámbito de instituciones de enseñanza media. No es extraño en este contexto, que, de manera progresiva, el acceso a las mismas cátedras y puestos docentes de la institución pasase a constituir una aspiración cada vez más fuerte de los estudiantes que estaban próximos a finalizar su carrera y de los graduados recientes.

En este sentido, cabe destacar que los modos y criterios de designación de los profesores suplentes constituyeron una fuente de controversias entre las autoridades y los estudiantes en más de una oportunidad. Estos últimos hicieron de aquellos blanco de sus críticas, lo que revelaba en principio cierta disconformidad con el modo en que eran designados, pero también cierta cercanía y familiaridad. A principios de 1907, un masivo nombramiento de profesores suplentes fue objeto de fuertes críticas por parte de los miembros del CEFYL. Sostuvieron en una nota dirigida al entonces Decano, José Nicolás Matienzo, que esas designaciones habían provocado "profunda impresión y general descontento". Algunos de estos profesores suplentes, afirmaban, aludiendo en particular a Alfredo Colmo, Enrique del Valle Iberlucea, Ricardo Cranwell y Pablo Cárdenas, "han sido condiscípulos de alumnos que actualmente cursan años superiores, sin descollar por cierto entre ellos, circunstancia que, como el señor Decano sabe, les quita la autoridad moral y el ascendiente intelectual que necesariamente debieran llevar a la cátedra". Por otro lado, sostenían, otro grupo de profesores suplentes que no habían sido alumnos de la casa, como Mauricio Nirenstein y Silvio Magnasco, no contaban con trabajos publicados ni de mérito, "ni tampoco han dictado cursos que les sirvan para dirigir los estudios que se siguen en nuestra Facultad". ${ }^{17}$ Más adelante, fueron algunas de las lecciones dictadas por estos profesores las que resultaron objeto de críticas. El caso del profesor de Latín Enrique Cranwell constituyó uno de los más controvertidos. Los estudiantes pidieron que se elevara un sumario sobre la base de su desconocimiento de aspectos básicos de la disciplina, como los relacionados con la morfología y la prosodia latina. En este contexto, señalaron: "Lo que sabe no sería suficiente para que le aprobaran el primer año de los colegios nacionales de Austria o Alemania, y eso como alumno, no como profesor" ${ }^{18}$

La relación con los profesores titulares, que, como ya hemos destacado, gozaban de mayores privilegios y estabilidad, y que cumplían además un papel mucho más decisivo en el gobierno universitario, conservó un tono mucho más respetuoso. Desde un principio procuraron los miembros del Centro asociar a varios de ellos como miembros protectores de la organización. En los inicios, asumir tal condición fue propuesto a figuras como José Nicolás Matienzo, Carlos Octavio Bunge, Samuel Lafone Quevedo y Antonio Dellepiane. La práctica de vincular a ciertos profesores a la organización en su condición de "protectores" se mantuvo a lo largo del período aquí analizado. También fue habitual la realización de homenajes a profesores fallecidos. Es evidente, además, que mantenían vínculos particularmente estrechos con algunas figuras destacadas del cuerpo docente. El caso de Ricardo Rojas, que colaboró en más de una oportunidad en las revistas del CEFYL, es un ejemplo en ese sentido.

Sin embargo, también es posible advertir, en algunos casos, la protesta y movilización de los estudiantes para desplazar a ciertos profesores titulares aun antes de la constitución del CEFYL. En marzo de 1904, un grupo de alumnos solicitó el desplazamiento del profesor de Ciencia de la Educación Francisco Berra. El motivo era su enseñanza dogmática, su escasa familiaridad con los procedimientos científicos y, paradójicamente, su falta de método y plan didáctico. Ya en vísperas del movimiento de la Reforma, se opondrían al desplazamiento del profesor Rodolfo Senet y a la designación de Julio C. Moreno. Este último había llegado no gracias a sus méritos científicos, sino, afirmaban, merced a sus vínculos políticos. Aquí aparecía, una vez más, el cuestionamiento a la política criolla como un motivo esencial de la protesta. Finalmente, es llamativa la preocupación de los estudiantes por organizar ciclos de conferencias, y por invitar a especialistas en las disciplinas que se enseñaba en la Facultad y que no formaban parte del cuerpo docente. Adolfo Saldías, Florentino Ameghino, Leopoldo Lugones fueron invitados a dar conferencias en la institución. Este tipo de acciones revelaba, de algún modo también, cierta disconformidad con las actividades y el perfil de los docentes de la casa. 


\section{PoLÍTICA Y RELIGIÓN}

Las comisiones directivas del Centro estuvieron integradas por figuras que, años después, cumplirían un papel relevante en la vida de la Facultad, de la Universidad de Buenos Aires en general, e incluso de la política de la ciudad y la nación. Los nombres de Salvador Debenedetti, Coriolano Alberini y, sobre todo, Emilio Ravignani se reiteran con frecuencia en las primeras actas de sesiones del CEFYL. Debenedetti desarrollaría una larga carrera como profesor en la institución y llegó a ser director de uno de sus organismos más importantes, el Museo Etnográfico. Alberini también desarrollaría una carrera académica exitosa y llegó a ser Decano en dos oportunidades. Ravignani, por su parte, no sólo ocuparía el cargo de Director de uno de los institutos más prestigiosos de la Facultad, el de Investigaciones Históricas, sino que también sería electo en dos oportunidades Decano e incluso por un tiempo muy breve ocuparía el Rectorado de la Universidad. Fue una figura relevante de la política porteña, en su condición de dirigente de la Unión Cívica Radical. Otros personajes centrales de la vida intelectual de aquellos años, como Alfredo Bianchi o Roberto Giusti, cumplirían un papel protagónico en la vida del CEFYL. Ya algunos años más tarde se destacaría Gregorio Bermann en el núcleo de los miembros del Centro, más tarde reconocido médico psiquiatra y dirigente socialista. Bermann, a su vez, fue reemplazado por Enrique Franois, quien sería vicedecano de la Facultad entre 1932 y 1936, y Delegado Interventor entre 1946 y 1949.

Estos hechos nos llevan a preguntarnos por los modos en que las cuestiones políticas se introdujeron en los debates y discusiones del CEFYL y por la forma en que fueron procesadas a lo largo de sus primeros años de vida. En este sentido, y como hemos señalado en trabajos previos (Buchbinder, 2008), creemos importante destacar que gran parte de la literatura sobre la Reforma de 1918 ha privilegiado en su análisis una perspectiva que pone énfasis en las proyecciones políticas del movimiento estudiantil y en la posterior inserción y protagonismo de sus principales dirigentes en la vida política nacional y latinoamericana. La Reforma, efectivamente, constituyó un acontecimiento de una enorme densidad política y que se articuló con una serie de episodios nacionales e internacionales que le otorgaron una impronta particular. Pero esta perspectiva ha ocluido a menudo la fuerza de la reivindicación corporativa y la relativa indiferencia e incluso prevención hacia la política nacional que caracterizó a gran parte del movimiento estudiantil desde sus orígenes a principios de siglo y que marcó también un sello característico de su actividad en los primeros años posteriores a la Reforma. Como hemos señalado aquí y hemos destacado en trabajos anteriores, es imposible comprender los orígenes del movimiento estudiantil de la UBA desconociendo la fuerza e intensidad de sus reivindicaciones corporativas.

El CEFYL mantuvo, en sus orígenes, una tesitura tendiente a asegurar la prescindencia de sus asociados en aquellas controversias relacionadas con la política nacional e internacional. En sus orígenes se estableció que la organización y sus miembros se mantendrían al margen de las polémicas "políticas y religiosas". En mayo de 1908 se produjo un debate en una de las sesiones de la Comisión Directiva del Centro a raíz de la publicación de un artículo periodístico en el que se mencionaba la participación de estudiantes de la Facultad y miembros del Centro en un banquete ofrecido por el Dr. Luis M. Drago. El episodio generó una fuerte polémica entre los socios presentes. Algunos de ellos recordaron que el estatuto prohibía a los integrantes del CEFYL mezclarse en cuestiones políticas y religiosas. ${ }^{19} \mathrm{El}$ acontecimiento permitió ratificar la disposición. Esto era, por otro lado, congruente con el Estatuto que había sancionado la recientemente creada FUBA, que en su artículo 29 establecía: "En ningún caso la Federación ni los centros que la componen podrá tomar participación en asuntos relacionados con la política y la religión”. ${ }^{20}$

Pero ya desde mediados de la década de 1910 el Centro comenzó a experimentar un proceso de mayor apertura hacia las cuestiones políticas e incluso de creciente diferenciación ante las autoridades de la Facultad, de la Universidad o de los funcionarios políticos nacionales. Las razones de esta limitada apertura pueden encontrarse, consideramos, en distintos factores. Creemos que es posible explicarla a partir del fracaso en el intento de obtener el tan ansiado reconocimiento de los títulos. Como señalamos anteriormente, esta 
circunstancia provocó un vínculo más conflictivo con la política nacional en la medida en que, interpretaban, eran las prácticas y vicios allí dominantes los que, según lo miembros de la agrupación, obturaban su acceso a los cargos de profesor. También es posible que se debiera a cambios en el contexto nacional e incluso internacional. La sanción de la ley Sáenz Peña, el proceso de democratización que lo siguió, junto al ascenso del radicalismo al poder y de Hipólito Yrigoyen a la Presidencia de la Nación, son factores que deben tenerse en cuenta en este análisis. A ellos deben sumarse, sin duda, las repercusiones del estallido de la Primera Guerra Mundial y, más tarde, la Revolución Rusa.

Pero consideramos que hay otro factor relevante a tener en cuenta y que se vincula con la creciente influencia y liderazgo dentro del Centro de Gregorio Bermann -que estudiaba también Medicina-, figura central del movimiento estudiantil e incluso del proceso reformista de 1918. Bermann asumió la dirección de Verbum en mayo de 1916 y luego fue electo Presidente del CEFYL. Su ascenso en la estructura de la organización fue gradual y sus posiciones e intervenciones, notorias desde 1914, fueron al principio muy resistidas. La vinculación más estrecha del Centro con círculos gremiales obreros y políticos, la visión cada vez más crítica del cuerpo de profesores, el impulso al apoyo al movimiento de solidaridad internacional con Julián Besteiro, profesor de Lógica de la Universidad de Madrid condenado a cadena perpetua por motivos políticos, fueron motorizados por Bermann durante su gestión al frente de Verbum primero y del CEFYL después. ${ }^{21}$ También impuso un vínculo más crítico con la política nacional en general a partir, entre otros aspectos, de los cuestionamientos a la designación de profesores suplentes y la formación de las ternas para la designación de los titulares. El caso del nombramiento del Profesor titular de Práctica y Crítica Pedagógica -Senet- es un ejemplo significativo ya que constituyó un motivo de fuerte conflicto en el que el Centro se manifestó contundentemente contra una decisión del Poder Ejecutivo. La Facultad, y luego la Universidad, habían elevado una terna para proveer de un profesor titular de dicha cátedra, encabezada por el nombre de Rodolfo Senet, entonces a cargo. Pero el Poder Ejecutivo eligió en cambio a Julio C. Moreno. El Centro, bajo el impulso de Bermann, inició una campaña a favor de Senet. La designación de Moreno fue interpretada como una afrenta a los fueros universitarios. Su designación, según los estudiantes, era producto de "enjuagues políticos". En ese sentido, sostuvieron que eran "perfectamente conocidas las vinculaciones del doctor Moreno con el Partido Radical”. 22 El papel de Bermann en la defensa de Senet fue central.

Pero estas intervenciones que asumían un vínculo nuevo con la política generaron también tensiones, lo que revela la fuerza de aquellos sectores que procuraban mantener las actividades de la organización al margen de aquella. El Centro se dividió en 1917, aparentemente por estas razones, y fue la intervención de la FUBA lo que logró revertir la división. El ascenso a fines de 1918 a la Presidencia del CEFYL de Enrique François, inclinado hacia posiciones más conservadoras y corporativas, pareció aquietar las aguas desde el punto de vista político.

\section{REFlexiones Finales}

Los estudiantes que fundaron el CEFYL en 1905 compartieron desde los orígenes de la organización un conjunto de reclamos y reivindicaciones con el conjunto de las agrupaciones gremiales que congregaban a los estudiantes de la UBA. Los cuestionamientos a aspectos básicos del funcionamiento del régimen universitario de principios del siglo XX, como los relativos a los sistemas de exámenes, de asistencia a clase o de correlatividades, constituyeron aspectos comunes a la mayoría de los Centros de la época y que también compartió el CEFYL. Otros, en cambio, como los vinculados con la exención del pago de derechos de matrícula ocuparon en este caso un lugar secundario, debido a políticas particulares de acceso a la Facultad impulsadas por las autoridades universitarias, motivadas a su vez por el escaso número de alumnos que esta congregaba.

El reclamo por la validez de los títulos para el acceso a los puestos en las cátedras de las escuelas medias constituyó un factor central del programa de reivindicaciones del CEFYL a lo largo de todo este período. 
En este contexto se construyó una identidad gremial y política muy asociada a la condición contemporánea y futura como profesores y maestros de los integrantes de la organización. La disputa con los gobiernos y autoridades políticas por los modos y criterios de acceso a los cargos en las mencionadas instituciones tuvieron un papel fundamental en las formas en que los estudiantes de la Facultad se situaron frente a la política en términos generales. La defensa de criterios meritocráticos frente a un sistema en el que primaban las "recomendaciones" y las prácticas clientelares fue un aspecto que distinguió a la agrupación. En estas prácticas operaban también modos de discriminación de género, a lo que tácitamente también se opuso la organización.

A la vez, el CEFYL construyó, en sus primeros años, una agenda fundamentalmente gremial, manteniendo una separación muy clara con respecto a dimensiones más amplias de la vida política nacional e internacional. Estos límites comenzaron a ser cuestionados fundamentalmente en los años previos a la Reforma, en gran medida por cambios en la coyuntura nacional e internacional pero también por el fracaso en lograr el reconocimiento de los títulos. La creciente influencia de figuras como Gregorio Bermann, que fue Director de la Revista Verbum primero y luego Presidente del CEFYL, también incidió en la progresiva politización de la organización. Al mismo tiempo, estas tendencias fueron resistidas internamente, lo que produjo una ruptura interna provisoria en 1917. Mas allá de esto, puede señalarse que durante este período, incluso adhiriendo tempranamente a los reclamos de los estudiantes cordobeses en 1918, los miembros del CEFYL conservaron una relación cordial con las autoridades de la UBA y de la misma Facultad, sin protagonizar, como ya señalamos, conflictos abiertos, lo que puede verse precisamente también con el análisis del proceso de la Reforma Universitaria en la misma institución.

\section{Bibliografía}

Barrancos, D. (2008). Mujeres entre la casa y la plaza. Buenos Aires: Sudamericana

Berruti, R. (1996). La creación de la Facultad de Filosofía y Letras. Buenos Aires:Edicion de autor.

Buchbinder, P. (2018). Reclamos Corporativos y compromisos políticos: una lectura de las juventudes universitarias argentinas en tiempos de la Reforma. Contemporánea, $\mathrm{N}^{\circ}$ 9... 9-34.

Buchbinder, P. (2008). ¿Una revolución en los claustros? La reforma de 1918. Buenos Aires: Sudamericana.

Bustelo, N. (2015). La reforma universitaria desde sus grupos y revistas: Una reconstrucción de los proyectos y las disputas del movimiento estudiantil porteño de las primeras décadas del siglo XX (1914-1928) (Tesis doctoral). Presentada en Universidad Nacional de La Plata. Facultad de Humanidades y Ciencias de la Educación para optar al grado de Doctora en Historia. Disponible en http://www.memoria.fahce.unlp.edu.ar/tesis/te.1307/te .1307.pdf. Consultada el 23/2/2017

Carreño, L. (2017). Pobrecitos jovencitos sin sexo y sin seso. Formas y modelos de vida estudiantil bajo la crítica de los reformistas de izquierda en la Universidad de Buenos Aires (1917- 1921). Izquierdas, $\mathrm{N}^{\circ} 32,2017,79-106$.

Carreño, L. (2018). Los caminos de la Reforma Universitaria. Sociabilidad y vida estudiantil en los centros de estudiantes de la Universidad de Buenos Aires (1900-1918). Quinto Sol, Vol. 22 (1), 1-22.

Ciria, A. y Sanguinetti, H. (1968). Los Reformistas. Buenos Aires: Jorge Álvarez Editor.

Dalmazzo, G. (1997). Línea Recta: estudiantes en lucha. Todo es Historia, N³60, 51-70.

Devoto, F. (2010). El pais del primer centenario. Buenos Aires: Capital Intelectual.

García, S. (2006). Ni solas ni resignadas: la participación femenina en las actividades científico-académicas de la Argentina en los inicios del siglo XX. Cadernos Pagu. N²7,133-142.

González, J. V. (1927). La Reforma Universitaria. Buenos Aires: Sagitario.

Graciano, O. (2008). Entre la torre de marfil y el compromiso político. Intelectuales de izquierda en la Argentina (1918-1955). Bernal: Editorial de la Universidad Nacional de Quilmes.

Halperín Donghi, T. (1962). Historia de la Universidad de Buenos Aires. Buenos Aires: Eudeba.

Ibarguren, C. (1977 [1955]). La historia que he vivido. Buenos Aires: Dictio. 
Lorenzo, M. F. (2016). Que sepa coser, que sepa bordar, que sepa abrir la puerta para ir a la Universidad. Las académicas de la Universidad de Buenos Aires en la primera mitad del siglo XX. Buenos Aires: Eudeba.

Pinkasz, D. (1992). Orígenes del profesorado secundario en la Argentina: tensiones y conflictos. En C. Braslavsky y A. Birgin. Formación de Profesores (pp.59-82). Buenos Aires: Miño y Dávila Editores.

Portantiero, J. C. (1977). Estudiantes y Politica en América Latina. 1918-1938: el Proceso de la Reforma Universitaria. México: Siglo XXI.

Rojkind, I. (2007). Estudiantes, Universidad y Politica en el Buenos Aires de 1900. XI Jornadas Interescuelas de Historia, Facultad de Filosofía y Letras, Universidad Nacional del Tucumán, Argentina. . Recuperado de http://cdsa.aa cademica.org/000-108/322.pdf

Sousa, P. (2007). El Círculo Médico Argentino y su papel en la configuración del pensamiento médico clínico (Buenos Aires 1875-1883). Entrepasados, 31, 141-181.

Suárez, P. (2012). Las mujeres abogadas en la Historia y en la Facultad de Derecho de la Universidad de Buenos Aires. Academia, $\mathrm{N}^{\circ} 20,143-183$.

Terrén de Ferro, D. (1985). Historia de la Instrucción Pública en la Argentina. Buenos Aires: Ediciones Universidad del Salvador.

Walter, R. (1968). Student Politics in Argentina. New York-London: Basic Books.

\section{Notas}

1 Memoria del Rectorado elevada el 7 de julio de 1900 al Señor Ministro de Justicia e Instrucción Pública, Osvaldo Magnasco, en Anales de la Universidad de Buenos Aires, Tomo XIV, 1901, pp. 13 y siguientes.

2 Narciso Binayán, "La Facultad de Filosofía y Letras", en Verbum, N 37-38, 1917, pp. 45-49.

3 Al Señor Decano de la Facultad de Filosofía y Letras, Dr. Lorenzo Anadón, marzo 26 de 1900, en Archivo de la Facultad de Filosofia y Letras, Caja 102, Foja 14.

4 Alumnos de la Facultad de Filosofía y Letras al Señor Decano de la Facultad, Dr. Lorenzo Anadón, 21 de marzo de 1899, en Archivo de la Facultad de Filosofia y Letras, Caja 102-B76, Legajo n 8, foja 102.

5 Acta ${ }^{\circ}$ 1, 30 de septiembre de 1905, en Actas de Reunión. Centro de Estudiantes. Facultad de Filosofia y Letras, UBA, 1905-1915, foja 1. A través de los ciclos de conferencias, el Centro se involucraría, sobre todo desde los años 20, en el desarrollo de la activa política de extensión de la Facultad.

6 Centro de estudiantes solicita personería, 1906, en Archivo de la Facultad de Filosofia y Letras, Caja 102-B76, foja 47.

7 Al Señor Decano de la Facultad de Filosofía y Letras, Dr. José Nicolás Matienzo, 5 de agosto de 1906, en Archivo de la Facultad de Filosofia y Letras, Caja 102, foja 53.

8 "Manifiesto", en Verbum, $\mathrm{N}^{\circ} 20,1912$, pp. 1-3.

9 "Actas y Documentos del Centro. Sesión Ordinaria del 15 de Julio, en Boletin del Centro de Estudiantes de Filosofía y Letras, N 8-9, Agosto-Septiembre de 1907, pp. 127-128.

10 Jorge M. Piacentini, "Por los fueros", en Verbum, N 26, mayo de 1915, pp. 50-51.

11 Actas de reunión-Centro de Estudiantes. Facultad de Filosofía y Letras, UBA, 1905-1915, Sesión Extraordinaria del 8 de mayo de 1914. Fojas 152-153.

12 La Dirección, "La ley del profesorado secundario", en Verbum, No 31-32, Mayo-Junio de 1916, pp. 31-32.

13 Arturo Vázquez Cey, "La Facultad de Filosofía y Letras y la crisis actual de su enseñanza", en Verbum, No 35-36, mayojunio de 1917, pp. 85-87.

14 Raquel Camaña, "El prejuicio sexual y el profesorado en la Facultad de Filosofía y Letras", en Revista de Derecho, Historia $y$ Letras, Tomo 37, 1910, pp. 575-612.

15 "A los estudiantes", en Revista del Centro de Estudiantes de la Facultad de Filosofia y Letras, N 16 y 18, Junio-Julio de 1911, pp. 2-3.

16 J.M.P. "Par pari refertur", en Verbum, N 26, mayo de 1915, pp. 54-57.

17 Al Señor Decano de la Facultad de Filosofía y Letras, Dr. José Nicolás Matienzo, 25 de abril de 1907, en Actas de reunión. Centro de Estudiantes. Facultad de Filosofia y Letras UBA, 1905-1915. Foja 22.

18 "La enseñanza del Dr. Cranwell", en Boletin del Centro de Estudiantes de Filosofia y Letras, N 7, 1907, pp. $52-53$.

19 Sesión Extraordinaria del miércoles 13 de mayo de 1908, en Libro de Actas del Centro de Estudiantes de Filosofía y Letras, foja 55.

20 "Estatutos de la Federación Universitaria", en Libro de Actas del Centro de Estudiantes de Filosofía y Letras, fojas 61-72. 
21 Estudiantes de Filosofía y Letras. Homenaje a Julián Besteiro, en Verbum, 41-42-, 1918, pp. 73-74.

22 "La eliminación del Dr. Senet", en Verbum, 35-36, 1917, pp. 91-94. 